Article

\title{
The Cold-Regulated Genes of Blueberry and Their Response to Overexpression of VcDDF1 in Several Tissues
}

\author{
Aaron Walworth ${ }^{(D)}$ and Guo-qing Song * (iD \\ Plant Biotechnology Resource and Outreach Center, Department of Horticulture, Michigan State University, \\ East Lansing, MI 48824, USA; walwort8@anr.msu.edu \\ * Correspondence: songg@msu.edu; Tel.: +1-517-353-0384
}

Received: 4 April 2018; Accepted: 13 May 2018; Published: 23 May 2018

check for updates

\begin{abstract}
Expression of blueberry cold-regulated genes (VcCORs) could play a role in the variable cold hardiness of blueberry tissues. In this study, transcriptome comparisons were conducted to reveal expression of $\mathrm{VcCORs}$ in non-acclimated leaves, flower buds, and flowers of both non-transgenic and transgenic blueberries containing an overexpressed blueberry DWARF AND DELAYED FLOWERING gene $(V c D D F 1)$ as well as in fully chilled flower buds of non-transgenic blueberry. In non-transgenic blueberries, $57.5 \%$ of VcCOR genes showed differential expression in at least one of the three pairwise comparisons between non-acclimated leaves, flower buds, and flowers, and six out of nine dehydration-responsive element-binding factors showed differential expression. In addition, expression of $V c D D F 1$ was not cold-inducible in non-transgenic blueberries and had higher expression in flowers than in leaves or non-acclimated flower buds. In transgenic blueberries, overexpression of $V c D D F 1$ resulted in higher $V c D D F 1$ expression in leaves than in flower buds and flowers. $V c D D F 1$ overexpression enhanced expression of blueberry $C B F 1$ and $C B F 3$ in leaves and repressed expression of $C B F 3$ in both flower buds and flowers. Overall, the results revealed tissue-specific expression patterns of VcCORs. The responses of VcCORs to overexpression of $V c D D F 1$ suggest that it is possible to increase plant cold hardiness through overexpression of a non-cold-inducible gene.
\end{abstract}

Keywords: cold-regulated genes; C-repeat-binding factor; DDF1; dehydration-responsive element-binding factor; freezing tolerance; tissue-specific expression; Vaccinium corymbosum

\section{Introduction}

Deciduous fruits, such as apples, grapes, pears, stone fruits (e.g., peaches, nectarines, apricots, and cherries), and berries (e.g., blueberries, cranberries, pomegranate, and kiwifruits), are of importance for human health due to their unique nutritional and medicinal values, being packed with fiber, sugars, minerals, vitamins, and anti-oxidants. These deciduous fruit crops show a great diversity in their tolerance to extreme low/high temperatures [1-3]. The lowest temperature that a plant can survive is genetically controlled, but is affected by many factors, such as natural environment, acclimation, and plant developmental stage $[4,5]$.

Climate change during the past 40 years has caused a shift toward earlier onset of the growing season of trees (e.g., 2.3 days/decade in temperate Europe) [6-9]. The early warm weather can lead to fruit/nut trees flowering out-of-season, and the increased temperature fluctuation during plant bloom often turns seasonal frost into a danger causing freezing injuries to flowers and young fruits [9-11]. Thus, breeding to develop freezing-tolerant fruit cultivars is considered to be a long-term solution to secure deciduous fruit production [9].

The low-temperature regulatory network in Arabidopsis thaliana consists of approximately 2500-4000 cold-regulated (COR) genes although tissue specificity of the expression of these COR genes 
has not been documented [12,13]. Of the COR genes, C-repeat-binding factor/dehydration-responsive element-binding factor 1 (CBF/DREB1) transcription factors have been well-studied due to their significant roles in tolerance to abiotic stresses, such as cold, drought, and salinity [13-22]. $C B F / D R E B 1$-mediated freezing tolerance seems to be conserved in woody fruit crops, although freezing tolerance induced by manipulation of $\mathrm{CBF}$ pathway genes could vary among plant species or even between tissues [18,23-28]. For example, ectopic expression of CBF1 in strawberry increased freezing tolerance in leaves but not in receptacles [29].

Michigan ranks number one in highbush blueberry production in the United States [30,31]. The winter freezing tolerance of buds and susceptibility of buds and flowers to spring frosts are considered important genetic limitations of highbush blueberry cultivars, and the cold hardiness of blueberry buds increases during acclimation and decreases during de-acclimation and dormancy-break [32]. Constitutive expression of a highbush blueberry (Vaccinium corymbosum) DWARF AND DELAYED FLOWERING 1 (DDF1) gene (VcDDF1) enhances freezing tolerance in leaves and flower buds but not in flowers [33], and transcriptome analysis has revealed that the altered expression of blueberry cold-regulated genes (VcCORs) in response to overexpression of VcDDF1 was responsible for the increased freezing tolerance of transgenic blueberry buds [34]. In this study, transcriptome analyses were conducted to reveal tissue-specificity of the expressions of VcCORs in both non-transgenic and transgenic tissues containing VcDDF1. The profiles of the identified differentially expressed (DE) VcCORs in 11 comparisons are anticipated to be useful for further investigation on gene networks for cold hardiness in blueberries.

\section{Results}

\subsection{Orthologues of Arabidopsis Cold-Regulated Genes in Blueberry}

All analyses were based on high-quality RNA sequencing data of three biological replicates/plants and two technical repeats per replicate for each type of sample tested. In our blueberry transcriptome reference (GenBank accession number: SRX2728597), 24,594 transcripts of VcCORs that showed high similarities (e <-20) to 2181 Arabidopsis CORs (AtCORs) were annotated to 5326 unique genes using Trinotate (Table 1; Table S1). These annotated VcCORs were used for transcriptome comparisons in different tissues in this study and are useful for future studies on freezing tolerance in blueberries.

Orthologues of approximately $50 \%$ of the AtCORs showed differential expression in each of the three transcriptome comparisons for non-acclimated blueberry tissues, including leaf versus bud, bud versus flower, and leaf versus flower (Table 1; Table S1). In total, orthologues of 1253 AtCORs showed differential expression in at least one of the three comparisons, and orthologues of 928 AtCORs did not show differential expression in any of the three comparisons. A further comparison revealed the difference between the three groups of the DE AtCOR orthologues (Figure 1A,B; Table S2). 
Table 1. Summary of transcriptome comparisons used to identify differentially expressed (DE) orthologues of AtCORs in different blueberry tissues.

\begin{tabular}{|c|c|c|c|c|c|}
\hline Source of Transcripts & Transcriptome Comparison & $\begin{array}{c}\text { Percentage } \\
\text { (Number) of } \\
\text { AtCORs that Have } \\
\text { DE Blueberry } \\
\text { Orthologues) }\end{array}$ & $\begin{array}{c}\text { Percentage (Number) of } \\
\text { Unique Genes out of the } \\
\text { Annotation of the DE } \\
\text { VcCORs ** (Annotated } \\
\text { by Trinotate) }\end{array}$ & $\begin{array}{l}\text { Total Number of } \\
\text { AtCORs that } \\
\text { Have (DE) } \\
\text { Blueberry } \\
\text { Orthologues) }\end{array}$ & $\begin{array}{c}\text { Total Number of Unique } \\
\text { Genes out of the } \\
\text { Annotation of the (DE) } \\
\text { VcCORs (Annotated by } \\
\text { Trinotate) }\end{array}$ \\
\hline $\begin{array}{l}\text { Blueberry transcriptome reference: } \\
\text { reftrinity }\end{array}$ & & & & 2181 & 5326 \\
\hline Bluecrop leaf (MID5) * & & & & 511 & 685 \\
\hline Bluecrop bud (MID10: $0 \mathrm{CU}$ ) * & & & & 687 & 996 \\
\hline Bluecrop bud (MID4: $397 \mathrm{CU}$ ) * & & & & 620 & 874 \\
\hline Bluecrop bud (MID1: 789 CU) * & & & & 610 & 873 \\
\hline Bluecrop bud (MID2: $1333 \mathrm{CU}$ ) * & & & & 553 & 802 \\
\hline $\begin{array}{l}\text { Bluecrop leaf and bud (MID5, MID10, } \\
\text { MID4, MID1, and MID2) * }\end{array}$ & & & & 1169 & 1960 \\
\hline \multirow[t]{5}{*}{ Legacy } & Leaf versus flower & $49.2 \%(1074 / 2181)$ & $58.7 \%(3126 / 5326)$ & (1074) & $(3126)$ \\
\hline & Flower versus non-acclimated bud & $52.9 \%(1154 / 2181)$ & $69.1 \%(3678 / 5326)$ & $(1154)$ & $(3678)$ \\
\hline & Leaf versus non-acclimated bud & $50.8 \%(1108 / 2181)$ & $61.8 \%(3293 / 5326)$ & (1108) & (3293) \\
\hline & Flower versus chilled bud & $51.9 \%(1131 / 2181)$ & $64.5 \%(3434 / 5326)$ & (1131) & (3434) \\
\hline & Chilled bud versus non-acclimated bud & $43.7 \%(953 / 2181)$ & $49.5 \%(2639 / 5326)$ & (953) & (2639) \\
\hline \multirow[t]{3}{*}{ Legacy-VcDDF1-OX } & Leaf versus flower & $49.9 \%(1089 / 2181)$ & $59.7 \%(3178 / 5326)$ & 1089 & (3178) \\
\hline & Flower versus non-acclimated bud & $52.7 \%(1150 / 2181)$ & $67.7 \%(3606 / 5326)$ & 1150 & (3606) \\
\hline & Leaf versus non-acclimated bud & $53.0 \%(1156 / 2181)$ & $66.5 \%(3542 / 5326)$ & 1156 & (3542) \\
\hline \multirow[t]{3}{*}{ Legacy and Legacy-VcDDF1-OX } & Legacy-VcDDF1-OX leaf versus Legacy leaf & $12.9 \%(282 / 2181)$ & $7.4 \%(396 / 5326)$ & 282 & (396) \\
\hline & Legacy-VcDDF1-OX flower versus Legacy flower & $11.4 \%(248 / 2181)$ & $6.9 \%(365 / 5326)$ & 248 & (365) \\
\hline & $\begin{array}{l}\text { Non-acclimated Legacy-VcDDF1-OX bud versus } \\
\text { non-acclimated Legacy bud }\end{array}$ & $17.8 \%(389 / 2181)$ & $12.1 \%(646 / 5326)$ & 389 & $(646)$ \\
\hline
\end{tabular}

* 454 expressed sequencing tag (EST) sequencing data (Available online: http:/ /bioinformatics.towson.edu/BBGD454/); ** blueberry cold-regulated genes (VcCORs): orthologues (e <-20) of 2181AtCORs. 


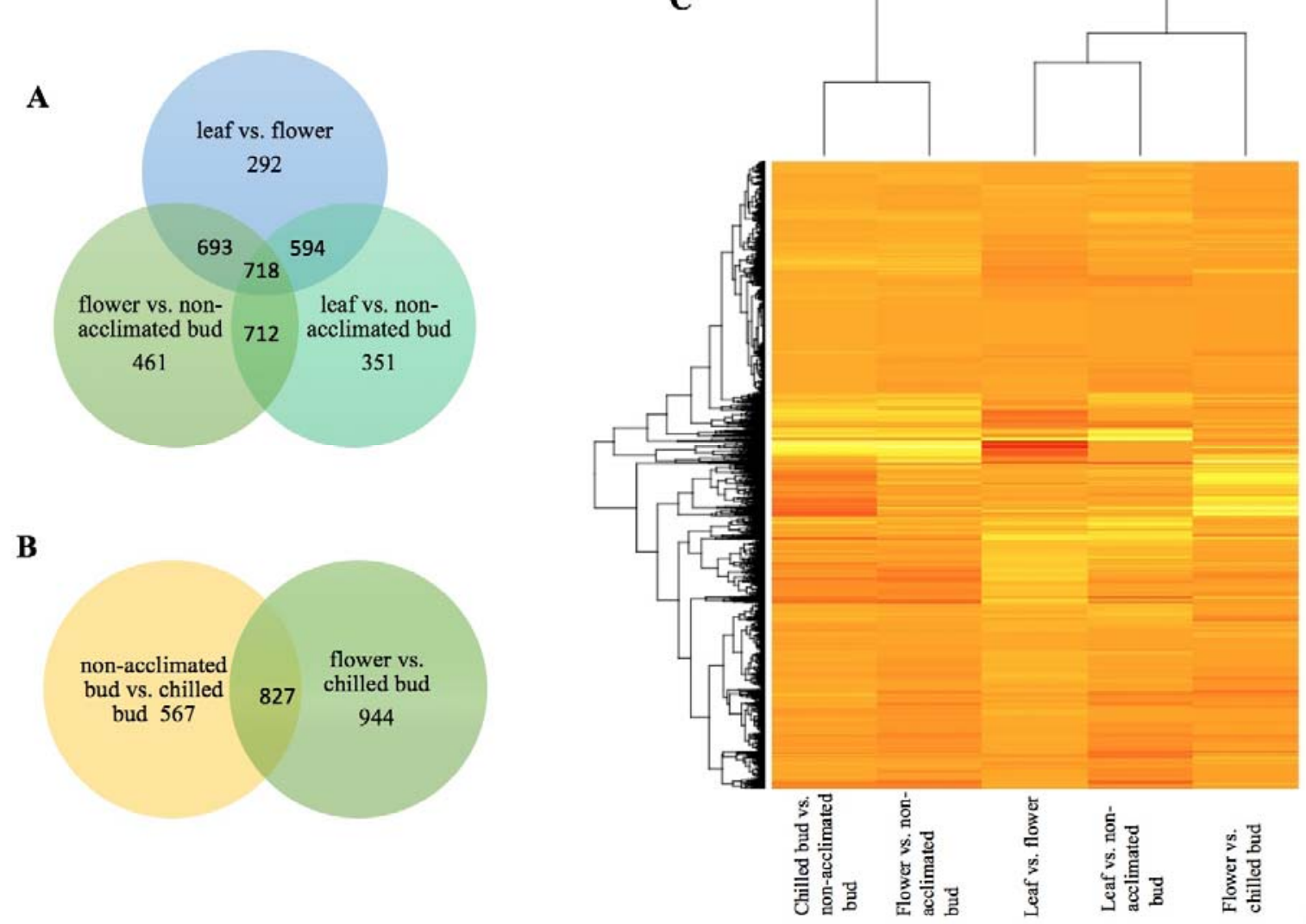

Figure 1. Differentially expressed (DE) orthologues of AtCORs in different tissues of non-transgenic 'Legacy'. (A) Comparisons between non-acclimated leaf, bud, and flower; (B) A comparison between chilled and non-acclimated buds; (C) Heat map of the DE VcCORs in different tissues of non-transgenic 'Legacy'. The heat map shows $\log _{2}$ Fold Change values for all DE VcCORs transcripts with a false discovery rate of less than 0.05 .

Expressed sequencing tags (ESTs) obtained by 454 sequencing in blueberry leaves and flower buds exposed to 4 chilling hours have been generated for a major highbush blueberry 'Bluecrop' [35]. Using the 2181 AtCORs to search for the presence of orthologous genes in the five EST libraries, orthologues of 1169 AtCORs were detected in 'Bluecrop'. In the five EST libraries, orthologues of 511 AtCORs were present in leaf tissues and orthologues of 553-687 AtCORs were detected in the four EST libraries for the flower buds exposed to 4 chilling hours. The non-acclimated flower buds showed more orthologues of AtCOR than the chilled flower buds (Table 1, Table S3).

\subsection{VcCORs and Freezing Tolerance}

In general, chilled blueberry flower buds are more tolerant to freezing than non-acclimated blueberry flower buds, and flowers are more vulnerable to freezing than both chilled and non-acclimated dormant buds [32]. Because of the importance of cold hardiness in dormant buds and flowers for blueberry production, DE VCCORs were identified and annotated in comparisons of chilled bud (>1000 chilling units) versus non-acclimated bud and flower versus chilled bud (Table 1; Figure 1B, C; Table S2). The chilled buds (compared to non-acclimated ones) showed DE orthologues of 953 AtCORs, and flowers (compared to chilled buds) had DE orthologues of 1131 AtCORs (Table 1). These DE VcCORs are likely responsible for the variation of freezing tolerance in these tissues.

The shared DE VCCORs were identified between three groups of DE VcCORs from the comparisons of chilled bud versus non-acclimated bud, chilled bud versus flower, and non-acclimated bud versus flower. Of the shared DE VcCORs, 309 VcCORs were upregulated and $225 \mathrm{VcCORs}$ were 
downregulated in all three groups (Figure 2A; Table S4). The gene network reveals the potential roles of these shared upregulated (309) and downregulated (225) DE VcCORs (Figure 2B; Table S4). Considering the comparison in each group was between tissues with a higher freezing tolerance and tissues with a lower freezing tolerance, these shared upregulated (309) and downregulated (225) DE VcCORs are likely responsible for the higher freezing tolerance in chilled buds (compared to non-acclimated bud and flowers) and in non-acclimated buds (compared to flowers). The VcDDF1 (isoform \# c32575_g1_i1) is among the 225 downregulated DE VcCORs (Table 2). Further analyses of the publically available EST (expressed sequence tag) data of 'Bluecrop' flower buds showed that VcDDF1 (isoform \# c32575_g1_i1 and c62996_g1_i1) were present only in non-acclimated flower buds in the four EST libraries for 'Bluecrop' flower buds with different chilling hours (Table S3). These results suggest that the $V c D D F 1$ is not cold inducible.

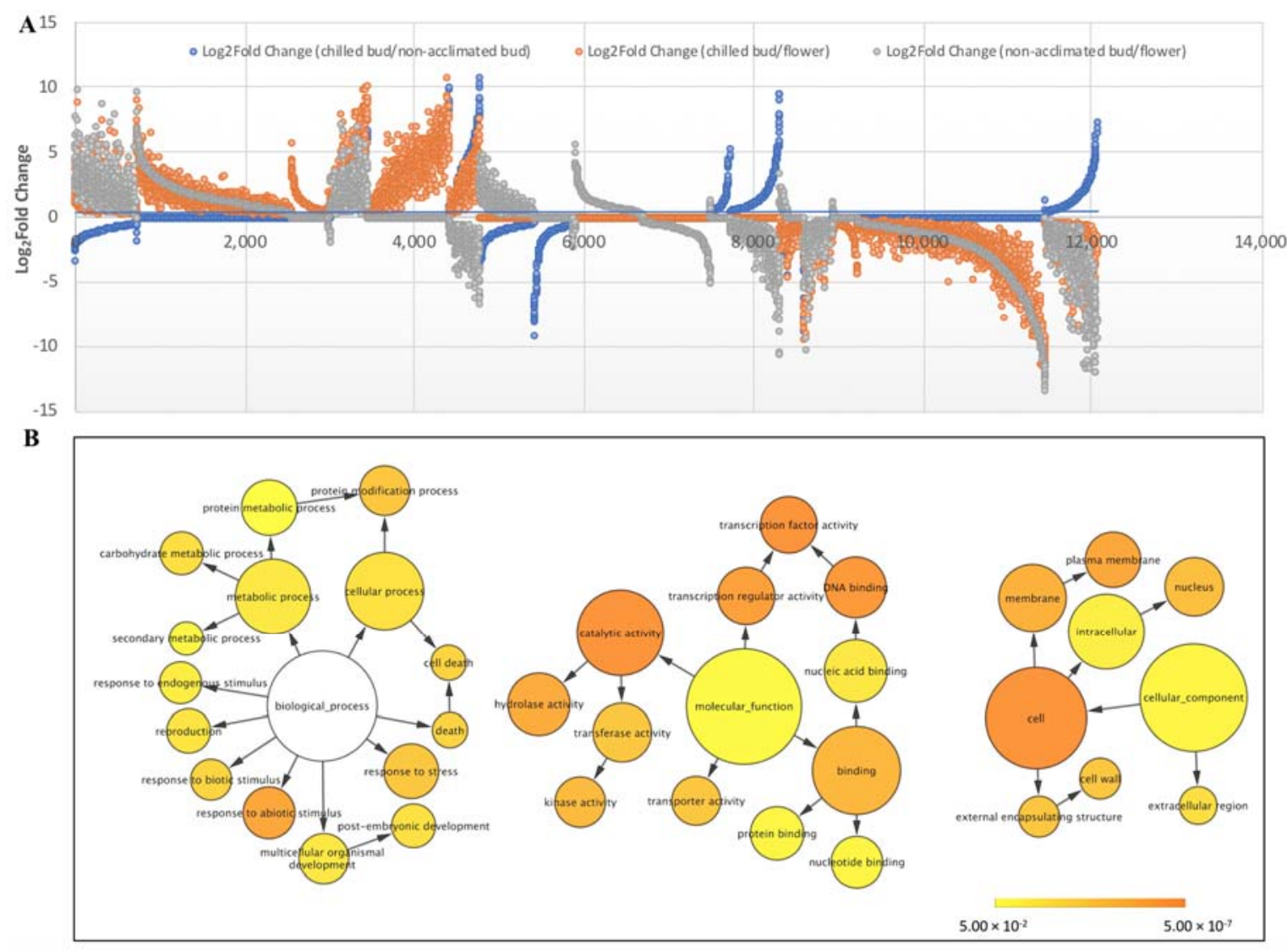

Figure 2. Differentially expressed (DE) VcCORs identified in transcriptome comparisons between high freezing tolerance tissues and low freezing tolerance tissues. (A) $\log _{2}$ Fold Change values for all DE VcCORs transcripts with a false discovery rate of less than 0.05 ; (B) Gene networks of the DE VcCORs transcripts in (A). The ontology file of GOSlim_Plants in BiNGO was used to identify overrepresented GO terms $(P<0.05)$. Bubble size and color indicate the frequency of GO term and $P$-value, respectively. 
Table 2. Differential expression of CBF/DREB1 and DREB2 transcription factors in different comparisons.

\begin{tabular}{|c|c|c|c|c|c|c|c|c|c|c|c|c|c|c|c|c|}
\hline \multirow[t]{2}{*}{ Transcript } & \multirow[t]{2}{*}{ Arabidopsis1 } & \multirow[t]{2}{*}{$\begin{array}{l}\text { Transcription } \\
\text { Factors }\end{array}$} & \multirow[t]{2}{*}{ E-Value } & \multirow[t]{2}{*}{ Annotation } & \multicolumn{3}{|c|}{$\begin{array}{c}\text { Log }_{2} \text { Fold Change } \\
\text { (Legacy-VcDD1-OX/Legacy) } \\
\end{array}$} & \multicolumn{6}{|c|}{$\log _{2}{ }^{\text {Fold Change }}$ for Legacy } & \multicolumn{3}{|c|}{$\begin{array}{l}\log _{2}{ }^{\text {Fold Change }} \text { for } \\
\text { Legacy-VcDDF1-OX }\end{array}$} \\
\hline & & & & & Leaf & $\begin{array}{l}\text { Non- } \\
\text { Acclimated } \\
\text { Buds }\end{array}$ & Flower & $\begin{array}{l}\text { Chill } \\
\text { Bud/Non- } \\
\text { Acclimated } \\
\text { Bud }\end{array}$ & $\begin{array}{l}\text { Flower/ } \\
\text { Chilled } \\
\text { Buds }\end{array}$ & $\begin{array}{l}\text { Leaf/ } \\
\text { Flower }\end{array}$ & $\begin{array}{l}\text { Flower/ } \\
\text { Non- } \\
\text { Acclimated } \\
\text { Bud }\end{array}$ & $\begin{array}{l}\text { Leaf/ Non- } \\
\text { Acclimated } \\
\text { Bud }\end{array}$ & Specificity & $\begin{array}{l}\text { Leaf/ } \\
\text { Flower }\end{array}$ & $\begin{array}{c}\text { Flower/ } \\
\text { Non- } \\
\text { Acclimated } \\
\text { Bud }\end{array}$ & $\begin{array}{c}\text { Leaf/ } \\
\text { Non- } \\
\text { Acclimated } \\
\text { Bud }\end{array}$ \\
\hline c88132_g2_i2 & AT4G25490 & CBF1 & $2.00 \times 10^{-21}$ & DRE1B_ARATH & 3.21 & $\# \mathrm{~N} / \mathrm{A}$ & $\# \mathrm{~N} / \mathrm{A}$ & $\# \mathrm{~N} / \mathrm{A}$ & $\# \mathrm{~N} / \mathrm{A}$ & \#N/A & $\# \mathrm{~N} / \mathrm{A}$ & \#N/A & $\begin{array}{l}\text { leaf }=\text { bud } \\
=\text { flower }\end{array}$ & 3.70 & $\# \mathrm{~N} / \mathrm{A}$ & 3.93 \\
\hline c75369_g2_i1 & AT4G25470 & CBF2 & $3.00 \times 10^{-21}$ & ERF38_ARATH & $\# \mathrm{~N} / \mathrm{A}$ & $\# \mathrm{~N} / \mathrm{A}$ & $\# \mathrm{~N} / \mathrm{A}$ & $\# \mathrm{~N} / \mathrm{A}$ & \#N/A & $\# \mathrm{~N} / \mathrm{A}$ & \#N/A & \#N/A & $\begin{array}{l}\text { leaf }=\text { bud } \\
=\text { flower }\end{array}$ & 3.08 & $\# \mathrm{~N} / \mathrm{A}$ & 1.76 \\
\hline c85919_g2_i1 & AT4G25470 & $\begin{array}{l}\text { CBF2, CBF1, CBF4, } \\
\text { CBF3, DDF1 }\end{array}$ & $5.00 \times 10^{-45}$ & DRE1F_ORYSJ & \#N/A & \#N/A & $\# \mathrm{~N} / \mathrm{A}$ & \#N/A & 4.50 & -1.88 & 2.67 & \#N/A & $\begin{array}{l}\text { leaf }=\text { bud } \\
<\text { flower }\end{array}$ & $\# \mathrm{~N} / \mathrm{A}$ & $\# \mathrm{~N} / \mathrm{A}$ & \#N/A \\
\hline c85919_g2_i4 & AT4G25470 & $\begin{array}{l}\text { CBF2, CBF1, CBF4, } \\
\text { CBF3, DDF1 }\end{array}$ & $3.00 \times 10^{-45}$ & DRE1F_ORYSJ & $\# \mathrm{~N} / \mathrm{A}$ & \#N/A & $\# \mathrm{~N} / \mathrm{A}$ & -2.20 & 5.80 & -2.48 & 4.35 & \#N/A & $\begin{array}{l}\text { leaf }=\text { bud } \\
<\text { flower }\end{array}$ & \#N/A & 4.04 & 4.03 \\
\hline c85919_g2_i5 & AT4G25470 & $\begin{array}{l}\text { CBF2, CBF1, CBF4, } \\
\text { CBF3, DDF1 }\end{array}$ & $6.00 \times 10^{-45}$ & DRE1F_ORYSJ & \#N/A & \#N/A & \#N/A & $\# \mathrm{~N} / \mathrm{A}$ & 4.50 & -2.30 & 5.45 & \#N/A & $\begin{array}{l}\text { leaf }=\text { bud } \\
<\text { flower }\end{array}$ & \#N/A & 4.23 & 4.84 \\
\hline c85919_g2_i6 & AT4G25470 & $\begin{array}{l}\text { CBF2, CBF1, CBF4, } \\
\text { CBF3, DDF1 }\end{array}$ & $3.00 \times 10^{-45}$ & DRE1F_ORYSJ & \#N/A & \#N/A & $\# \mathrm{~N} / \mathrm{A}$ & $\# \mathrm{~N} / \mathrm{A}$ & 5.10 & -3.42 & 6.06 & \#N/A & $\begin{array}{l}\text { leaf }=\text { bud } \\
<\text { flower }\end{array}$ & \#N/A & 4.97 & 4.42 \\
\hline c82156_g1_i1 & AT4G25470 & $\mathrm{CBF} 2, \mathrm{DDF} 1$ & $1.00 \times 10^{-22}$ & ERF23_ARATH & \#N/A & \#N/A & $\# \mathrm{~N} / \mathrm{A}$ & \#N/A & -3.90 & 6.35 & -4.69 & 1.67 & $\begin{array}{c}\text { flower }< \\
\text { bud }<\text { leaf }\end{array}$ & 5.32 & -2.57 & 2.78 \\
\hline c91057_g4_i1 & AT4G25470 & CBF2, DDF1, CBF1 & $2.00 \times 10^{-26}$ & ERF43_ARATH & \#N/A & \#N/A & $\# \mathrm{~N} / \mathrm{A}$ & -1.80 & -5.30 & \#N/A & -7.56 & -6.37 & $\begin{array}{c}\text { leaf }= \\
\text { flower }< \\
\text { bud }\end{array}$ & $\# \mathrm{~N} / \mathrm{A}$ & -9.70 & -8.40 \\
\hline c97417_g2_i1 & AT4G25470 & $\begin{array}{l}\text { CBF2, DDF1, CBF1, } \\
\text { CBF3, CBF4 }\end{array}$ & $2.00 \times 10^{-27}$ & TINY_ARATH & \#N/A & \#N/A & -0.65 & \#N/A & 3.10 & -1.24 & 2.63 & 1.37 & $\begin{array}{c}\text { bud }<\text { leaf } \\
<\text { flower }\end{array}$ & -1.57 & 2.69 & 1.13 \\
\hline c88132_g2_i1 & AT4G25480 & $\begin{array}{l}\text { CBF3, CBF2, CBF1, } \\
\text { CBF4, DDF1 }\end{array}$ & $2.00 \times 10^{-61}$ & DRE1A_ARATH & 2.47 & -1.87 & -2.96 & $\# \mathrm{~N} / \mathrm{A}$ & 2.90 & -2.63 & \#N/A & -2.06 & $\begin{array}{l}\text { leaf }<\text { bud } \\
=\text { flower }\end{array}$ & 2.78 & \#N/A & 2.21 \\
\hline c77615_g1_i1 & AT1G12610 & DDF1, CBF2 & $4.00 \times 10^{-27}$ & DREB3_ARATH & I \#N/A & \#N/A & \#N/A & \#N/A & -1.00 & 2.58 & -1.61 & \#N/A & $\begin{array}{l}\text { flower }< \\
\text { leaf }=\text { bud }\end{array}$ & \#N/A & \#N/A & $\# \mathrm{~N} / \mathrm{A}$ \\
\hline c87707_g1_i1 & AT1G12610 & DDF1, CBF2 & $5.00 \times 10^{-24}$ & DREB3_ARATH & I \#N/A & \#N/A & \#N/A & \#N/A & -0.90 & 1.51 & -1.16 & \#N/A & $\begin{array}{c}\text { flower < } \\
\text { leaf }=\text { bud }\end{array}$ & 1.46 & -1.20 & \#N/A \\
\hline c91057_g4_i3 & AT1G12610 & DDF1, CBF2 & $2.00 \times 10^{-23}$ & DREB3_ARATH & I \#N/A & \#N/A & \#N/A & -1.00 & -7.50 & 3.96 & -8.75 & -4.81 & $\begin{array}{l}\text { Flower }< \\
\text { leaf }<\text { bud }\end{array}$ & 2.69 & -8.23 & -5.54 \\
\hline c32575_g1_i1 & AT1G12610 & $\begin{array}{l}\text { DDF1, CBF2, CFB3, } \\
\text { CBF1, CBF4 }\end{array}$ & $2.00 \times 10^{-42}$ & DRE1E_ARATH & 7.64 & 7.27 & 4.54 & -2.20 & 4.80 & -2.26 & 3.25 & \#N/A & $\begin{array}{l}\text { leaf }=\text { bud } \\
<\text { flower }\end{array}$ & \#N/A & $\# \mathrm{~N} / \mathrm{A}$ & 1.31 \\
\hline c62996_g1_11 & AT1G12610 & $\begin{array}{l}\text { DDF1, CBF2, CFB3, } \\
\text { CBF1, CBF4 }\end{array}$ & $5.00 \times 10^{-44}$ & DRE1E_ARATH & 4.61 & $\# \mathrm{~N} / \mathrm{A}$ & 3.96 & \#N/A & $\# \mathrm{~N} / \mathrm{A}$ & \#N/A & $\# \mathrm{~N} / \mathrm{A}$ & $\# \mathrm{~N} / \mathrm{A}$ & $\begin{array}{l}\text { leaf }=\text { bud } \\
=\text { flower }\end{array}$ & $\# \mathrm{~N} / \mathrm{A}$ & $\# \mathrm{~N} / \mathrm{A}$ & $\# \mathrm{~N} / \mathrm{A}$ \\
\hline
\end{tabular}

\#N/A: No differential expression. 


\subsection{Expression of VcCORs in Legacy-VcDDF1-OX Plants}

$V c D D F 1-O X$ enhances freezing tolerance in dormant plants, leaves, and flower buds, but not significantly in flowers [33,34]. DE VcCORs, $7.4-12.1 \%$ of the total VcCORs, were identified in three tissues (leaf, non-acclimated floral bud, and flower) from the comparisons between transgenic Legacy-VcDDF1-OX and non-transgenic 'Legacy' (Table 1). The profiles of the DE VcCORs varied among different tissues, where the DE VcCORs in bud showed a higher similarity to those in flower than in leaf tissues (Figure 3A). DE orthologues of 38 AtCORs were identified for all three tissues; these DE orthologues were annotated to 31 unique genes, of which 3 were downregulated and 6 were upregulated in all three tissues, and fold changes of the remaining 22 genes are inconsistent in the three tissues (Figure 3B,C; Table S5).
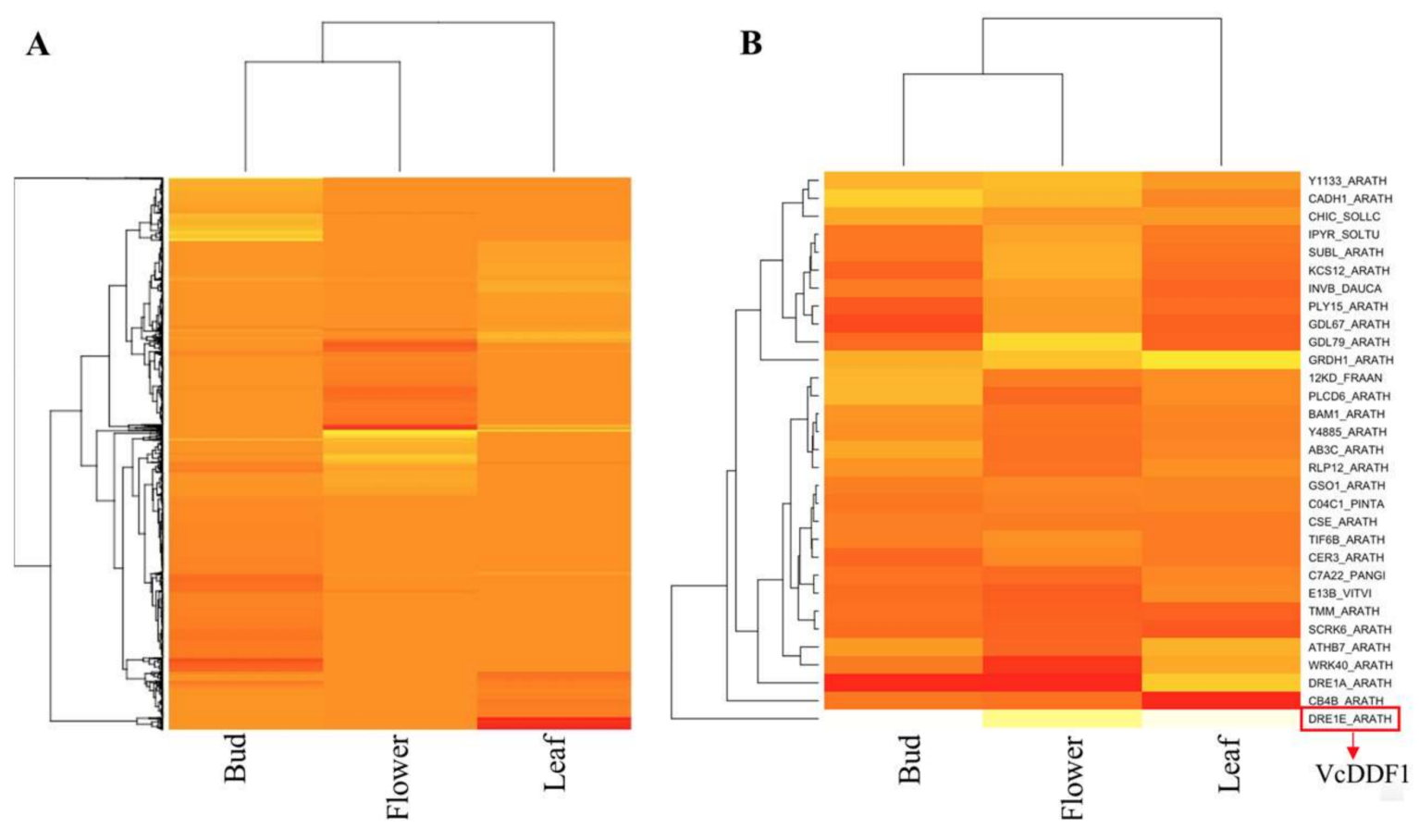

C

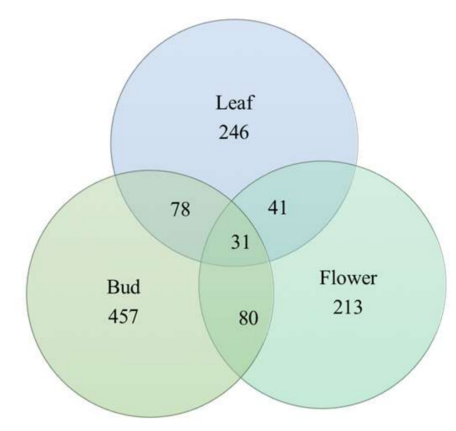

Figure 3. Differentially expressed (DE) VcCORs in different tissues of transgenic "Legacy-VcDDF1-OX". (A) Heat map of all the DE VcCOR transcripts in the three comparisons. The heat map shows $\log _{2}$ Fold Change values for all DE VcCOR transcripts with a false discovery rate of less than 0.05; (B) Heat map of the shared DE VcCOR genes (based on annotation) in the three comparisons. The heat map shows $\log _{2}$ Fold Change values (means of DE transcripts) for the shared DE VcCORs genes with a false discovery rate of less than 0.05 ; (C) Comparisons of DE orthologues of AtCORs in different blueberry tissues. The numbers are the numbers of AtCORs. 
DE VcCORs were also identified for transgenic Legacy-VcDDF1-OX plants in three transcriptome comparisons, including leaf versus bud, leaf versus flower, and flower versus bud (Table 1; Table S6). These DE VcCORs, in addition to those identified in non-transgenic 'Legacy' (Table 1), revealed the effect of the overexpression of $V c D D F 1$ on tissue-specificity of the VcCORs.

\subsection{Blueberry CBF/DREB1 Genes}

Using $C B F / D R E B 1$ genes (i.e., including $C B F 1-4, D D F 1$, and DDF2) as queries, $V c C B F 1-3$ and $V c D D F 1$ ( $<<-20)$ were found in 'Legacy', which all, except $V c C B F 1$, showed differential expression in the comparisons of leaf versus bud, leaf versus flower, or bud versus flower (Table 2). In addition, unlike the cold-inducible CBFs in A. thaliana [36], neither VcCBF1-3 nor VcDDF1 showed upregulation in chilled buds when compared to non-acclimated buds (Table 2).

In non-transgenic 'Legacy' plants, two VcDDF1 homologues (c32575_g1_i1 and c62996_g1_i1) were detected. The c62996_g1_i1 did not show differential expression in the comparisons among leaf, bud, and flower tissues. Additionally, differential expression of the c62996_g1_i1 was not detected in the comparison between non-acclimated buds and chilled buds. In contrast, the c32575_g1_i1 had a higher expression in flower tissues than in both leaf and non-acclimated bud tissues and showed a lower expression in chilled buds than in non-acclimated buds (Table 2).

In transgenic Legacy-VcDDF1-OX plants, c32575_g1_i1 is the overexpressed VcDDF1. Compared to non-transgenic tissues of 'Legacy', increased expression of c32575_g1_i1 was detected in transgenic leaf (200-fold, as high as that in non-transgenic leaf), bud (154-fold), and flower (23-fold) tissues; the lower increase (23-fold) of the expression of c32575_g1_i1 in flower was due to the high c32575_g1_i1 expression in non-transgenic flower (Table 2). In the comparisons between transgenic tissues (leaf versus bud, leaf versus flower, and bud versus flower), expression of c32575_g1_i1 was 2.5-fold higher in leaf than in bud tissues, while differential expression of c32575_g1_i1 was not detected in the other two comparisons (Table 2). These results suggest that the lower increase of freezing tolerance in transgenic flowers (compared to that of leaves and buds) is not caused by the levels of $V c D D F 1-O X[33,34]$.

In the comparisons of transgenic tissues of Legacy-VcDDF1-OX to non-transgenic tissues of 'Legacy', the overexpressed $V c D D F 1$ resulted in upregulation of $V c C B F 1$ and $V c C B F 3$ in leaf tissues and downregulation of $V c C B F 3$ in both bud and flower tissues (Table 2). In addition, the overexpressed $V c D D F 1$ upregulated the expression of the VcDDF1 homologue c62996_g1_i1 in leaf and flower tissues but not bud tissues (Table 2).

\subsection{Validation of the Expression of VcDDF1}

QRT-PCR was conducted to validate the DE or non-DE VcDDF1 (c32575_g1_i1) in 11 transcriptome comparisons (Figure 4; Table 2). In non-transgenic 'Legacy', flowers showed a higher expression of $V c D D F 1$ than leaves and buds (chilled and non-acclimated), and non-acclimated buds had a higher $V c D D F 1$ expression than chilled buds, indicating that expression of $V c D D F 1$ is not cold-inducible. In transgenic Legacy-VcDDF1-OX plants, constitutive expression of $V c D D F 1$ was confirmed in all three tissues. The qRT-PCR results are consistent with the RNA-seq data (Table 2), suggesting that the result of RNA-seq data analysis in this study is reliable. 


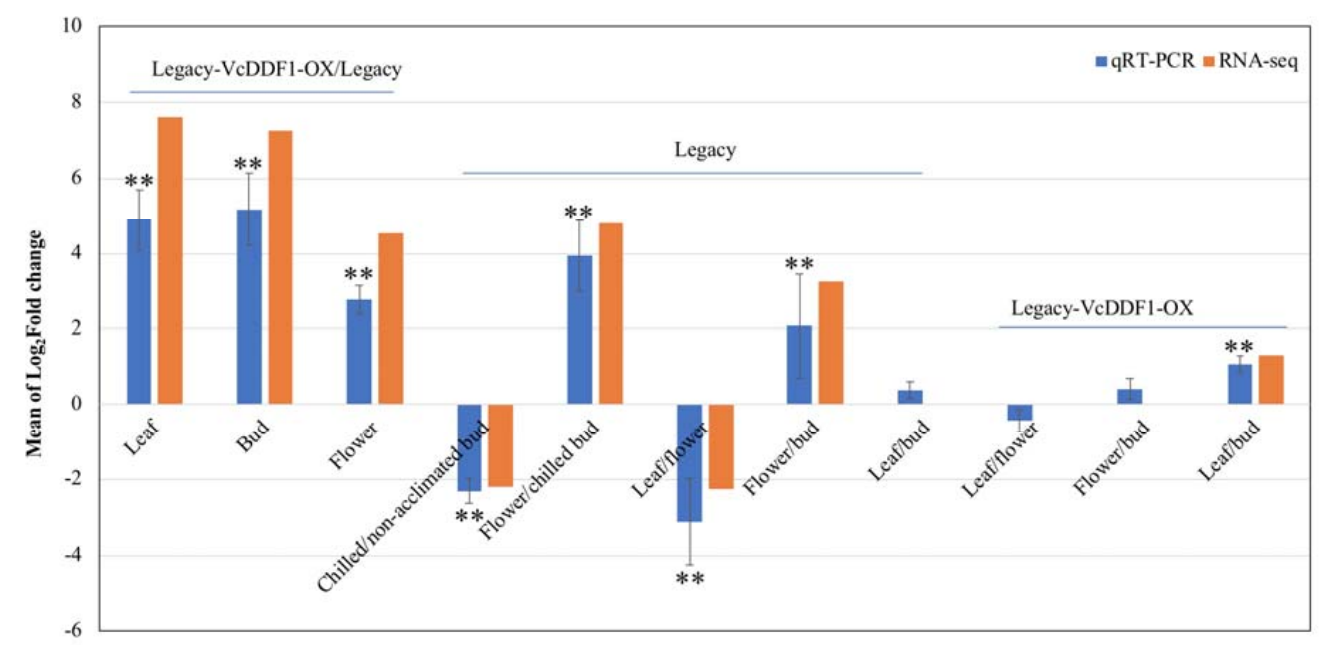

Figure 4. RNA sequencing and qRT-PCR analysis of VcDDF1 (c32575_g1_i1). Eukaryotic translation initiation factor 3 subunit $\mathrm{H}$ is the internal control. Relative expression $\log _{2}$ (Fold Change) in Legacy-VcDDF1-OX was calculated by $2^{-\Delta \Delta \mathrm{Ct}},-\Delta \Delta \mathrm{Ct}=-\left[\left(\mathrm{Ct}_{\mathrm{GOI}}-\mathrm{Ct}_{\text {nom }}\right)_{\text {Legacy-VcDDF1-OX }}-\left(\mathrm{Ct}_{\mathrm{GOI}}\right.\right.$ $\left.\left.-\mathrm{Ct}_{\text {nom }}\right)_{\text {Legacy }}\right]$. Average fold-changes $\pm \mathrm{STDEV}$ of three biological replicates/plants for each of Legacy-VcDDF1-OX and 'Legacy' plants were plotted. Significant average fold-change in qRT-PCR determined using a Student's $t$-test is denoted. Double asterisks $\left(^{* *}\right)$ indicate $P<0.01$. RNA-seq data show $\log _{2}$ Fold change values with a false discovery rate of less than 0.05 .

\section{Discussion}

Cold acclimation is an adaptive mechanism that has evolved to enhance cold hardiness. Functional genomics of cold acclimation is anticipated to lead to improved cold/freezing tolerance through breeding or genetic engineering.

\subsection{VcCOR Genes in Blueberry}

To date, tissue/organ specificity of the expression of COR genes in A. thaliana has not been well-documented. For deciduous fruit crops (e.g., blueberries), it is important to reveal the specificities of the COR orthologues because the breeding focus for improving cold hardiness is often on buds and flowers [32]. In this study, leaves and non-acclimated buds were harvested in mid-November prior to transferring the 'Legacy' and VcDDF-Legacy-OX plants from a heated greenhouse to natural outdoor environmental conditions. Flower and chilled bud tissues were collected from the plants after moving to natural environmental conditions. Arabidopsis CORs were used to identify VcCORs. The DE VcCORs in the comparison of leaf versus bud give an accurate depiction of organ-specificity of the $\mathrm{VcCORs}$ because the tissues were collected at the same time from the same plants. The DE VcCORs from other comparisons (i.e., leaf versus flower, chilled bud versus bud, flower versus bud, and flower versus chilled bud) revealed the difference of the expression of the VcCORs in these selected tissues (Table 1; Figure 1), although analysis of organ/tissue-specificity is confounded by the possibility of differential expression due to the effect of undocumented factors, such as the environmental conditions in which the tissues were harvested. Since the chilled buds and flowers were collected under natural growing conditions, where buds show a higher freezing tolerance than flowers and chilled buds have a higher freezing tolerance than non-acclimated buds [32], the DE VcCORs detected in the comparisons of chilled bud versus non-acclimated bud, flower versus non-acclimated bud, and flower versus chilled bud could facilitate future studies on the role of the VcCORs in the cold hardiness of blueberries.

\subsection{VcDDF1 and Freezing Tolerance}

The AP2/ERFs play a significant role in plant responses to several abiotic stresses (e.g., cold, dehydration, and high salinity), which has stimulated many recent studies on genome-wide analysis 
of the AP2/ERF in several plant species [17]. The CBF/DREB1 genes belong to a large family of the AP2/ERF transcription factors and have a conserved DNA binding domain recognizing the dehydration-responsive element/C-repeat (DRE/CRT) cis-acting element in the promoters of their target genes $[17,19,36]$. This CBF/DREB1 pathway has been well-documented in A. thaliana [19-22]. It appears that most of the plant species tested undergo cold acclimation through a universal process that belongs at least partially to the CBF/DREB1-mediated cold-response pathway [15-18,37].

As revealed in $A$. thaliana, the low-temperature regulatory network is more complicated than the CBF-CRT/DRE regulatory module $[12,13,38]$. For example, acclimation (cold) induces differential expression of 2637 cold-regulated (AtCOR) genes. In contrast, overexpression of CBF1, CBF2, and $C B F 3$ can only alter 171 (6.5\%) AtCOR genes. For deciduous fruit crops, many efforts have been focusing mainly on developing transgenic plants for freezing tolerance using $C B F$ or $C B F$ orthologues. The CBF-CRT/DRE regulatory module has not been well-studied through forward genetics or reverse genetics. In our recent studies, transcriptomic responses to overexpression of the VcDDF1 showed DE COR genes (compared to non-transgenic plants) that may contribute to an increase in freezing tolerance [34].

To date, no profile of DE VcCORs between different blueberry organs has been documented. ESTs in blueberry leaves and flower buds exposed to different chilling hours have been generated through 454 sequencing for a major highbush blueberry 'Bluecrop' [35]. In this study, profiles of DE VcCORs were developed for 11 comparisons (Table 1, Figure 1). Given that chilled/acclimated flower buds have a higher freezing tolerance than non-acclimated buds and non-acclimated buds show a higher freezing tolerance than flowers in blueberries [32,33], the DE CORs revealed in comparisons of the three groups (i.e., chilled bud versus non-acclimated bud, non-acclimated bud versus flower, and chilled bud versus flower) of DE COR genes facilitate our understanding of the potential COR genes that can be used to increase freezing tolerance in buds and flowers through manipulating those shared upregulated (309) and downregulated DE orthologues of 309 and 225 AtCORs, respectively (Figure 2).

DDF1 is not cold inducible in $A$. thaliana [12]. Similarly, the VCDDF1 is not cold inducible. This was supported both by our RNA-seq data and the EST data in the four EST libraries for 'Bluecrop' flower buds with different chilling hours (Table 2; Table S3). It is interesting that the non-cold-inducible $V c D D F 1$ functions as a promoter of freezing tolerance. In non-transgenic 'Legacy', flowers show a higher expression of $V c D D F 1$ than both leaves and buds (Table 2); physiologically, this seems to be consistent with our previous observation where flowers exhibited a lower $\mathrm{EL}_{50}$ (temperature at which $50 \%$ of maximum electrolyte leakage occurred) [33]. In addition, the overexpressed VcDDF1 resulted in increased freezing tolerance in transgenic VcDDF-Legacy-OX plants [34]. Transcriptome comparisons between transgenic and non-transgenic tissues (leaf, bud, and flower) revealed that the overexpressed $V c D D F 1$ changed the expression profile of the VcCORs (Figure 3), which could be responsible for the increased freezing tolerance. Unlike overexpression of cold-inducible CBFs, which often results in a trade-off impact between cold tolerance and plant growth in A. thaliana [13], overexpression of the cold-repressive $V c D D F 1$ increased freezing tolerance without obvious impact on plant growth [34].

\section{Method}

\subsection{Plant Materials}

Non-transgenic southern highbush blueberry 'Legacy' and a representative transgenic 'Legacy' (hereafter Legacy-VcDDF1-OX, previously named as II7) was used in this study.

Legacy-VcDDF1-OX contains a blueberry-derived CBF gene (AVI45245.1), which was designated as $B B-C B F[33,39]$ and renamed as VCDDF1 [34]. Production and phenotypic analysis of transgenic 'Legacy' events containing a CaMV 35S promoter-driven $V c D D F 1$ were described in our previous report [33].

Twelve plants for each of non-transgenic and transgenic 'Legacy' were obtained through micropropagation of in vitro cultured shoots. All plants unless otherwise mentioned were grown normally and were fully chilled ( $>1200$ chilling unit) in winter in a secured courtyard under natural light 
conditions at Michigan State University, East Lansing, Michigan (latitude 42.701847, longitude -84.482170). The average low and high temperatures in January are $-10.6{ }^{\circ} \mathrm{C}$ and $-1.8^{\circ} \mathrm{C}$, respectively (Available online: http:/ / www.usclimatedata.com/climate/east-lansing/michigan/united-states/usmi0248).

Non-acclimated flower buds (30-50 buds per plant) and leaves (2-3 g per plant) were collected in November from three plants for each of the non-transgenic 'Legacy' and transgenic Legacy-VcDDF1-OX before the plants were exposed to chilling treatments. Chilled flower buds (30-50 buds per plant) of 'Legacy' were from three plants grown in the courtyard with natural environmental conditions and were harvested at the end of January. Late-pink buds, 20-30 buds per plant, were harvested in April from three 'Legacy' and three Legacy-VcDDF1-OX plants grown in the courtyard. All tissues collected were frozen immediately in liquid nitrogen and stored at $-80^{\circ} \mathrm{C}$. Three biological replicates, defined as tissues from three plants, were used for transcriptome and quantitative RT-PCR (qRT-PCR) analysis [34].

\subsection{RNA Preparation, Sequencing, and de Novo Transcriptome Assembly}

Total RNA isolation, RNA sequencing using the Illumina HiSeq2500 platform, and de novo transcriptome assembly using the Trinity platform (trinity/20140413p1) [40] were described in our recent report [41].

\subsection{Differential Expression Analysis and Transcriptome Annotation}

RNA-seq reads of three biological replicates/plants and two technical replicates for each biological replicate were analyzed. These RNA-seq reads are available in Genbank (SRA accession: SRP103678). The paired reads were aligned to the transcriptome reference developed for 'Legacy' [41] and the abundance of each read was estimated using the Trinity command "align_and_estimate_abundance.pl". The Trinity command "run_DE_analysis.pl -method edgeR" was used for differential expression analysis. The DE genes or transcripts (relative to non-transgenic 'Legacy' unless other mentioned) with false discovery rate (FDR) values below 0.05 were used for further analyses [34]. Transcriptome annotation was performed using Trinotate_v2.0 (Available online: https://trinotate.github.io).

\subsection{Expressed Sequence Tags (ESTs) in Blueberry}

The ESTs of 'Bluecrop' leaves and flower buds at four different stages of cold acclimation were downloaded from the Blueberry Genomics Database website (Available online: http:/ / bioinformatics. towson.edu/BBGD454/). The retrieved sequences were used for VcCOR analysis using the tblastn command of BLAST+.

\subsection{Identification of the VcCORs}

The 2637 cold-regulated genes (CORs) identified in wild-type $A$. thaliana plants and 172 CORs differentially expressed at a warm temperature $\left(22^{\circ} \mathrm{C}\right)$ in transgenic $A$. thaliana plants overexpressing $C B F 1, C B F 2$, or CBF3 were obtained from Park et al. [12]. These CORs were used to identify their orthologues in blueberry (VcCORs).

Representative protein sequences of selected genes of $A$. thaliana were download from the TAIR server (Available online: https://www.arabidopsis.org/tools/bulk/sequences/index.jsp). The retrieved sequences were used to search for the transcriptome reference of blueberry (GenBank accession number: SRX2728597) using the tblastn command of BLAST+. The resultant transcripts that show e-values lower than -20 were used to screen the retrieved 'Bluecrop' EST sequences and the DE transcript list of each comparison.

\subsection{QRT-PCR Analysis}

The RNA samples used for RNA-sequencing were used for cDNA preparation. Reverse transcription of RNA to cDNA was performed using SuperScript II reverse transcriptase (Invitrogen, 
Carlsbad, CA, USA). The resulting cDNA of one microgram of RNA was diluted (volume 1: 4) in water and $1 \mu \mathrm{L} /$ sample ( $25 \mathrm{ng}$ ) was used for PCR reactions. PCR primers cbF3: 5'-ATTGGCGCTGAAAAGTGAGT-3' and cbR1: $5^{\prime}$-CGCTGCCCTCCTTATATGTT- $3^{\prime}$ that cover a 109-bp region of the VcDDF1 were used. Primers of eukaryotic translation initiation factor 3 subunit $H$ (VcEIF-F: 5'-GAGAGATTCAGATGCCCAGAAG-3' and VcEIF-R: GGACAATGGATGGACCAGATT) were the internal control. QRT-PCR was performed in triplicate (three biological controls) on an Agilent Technologies Stratagene Mx3005P (Agilent Technologies, Santa Clara, CA, USA) using the SYBR Green system (Life Technologies, Carlsbad, CA, USA). In each $25 \mu \mathrm{L}$ reaction mixture, $25 \mathrm{ng}$ cDNA, $200 \mathrm{nM}$ primers, and $12.5 \mu \mathrm{L}$ of $2 \times$ SYBR Green master mix were included. The reaction conditions for all primer pairs were $95^{\circ} \mathrm{C}$ for $10 \mathrm{~min}, 40$ cycles of $30 \mathrm{~s}$ at $95^{\circ} \mathrm{C}, 60 \mathrm{~s}$ at $60^{\circ} \mathrm{C}$, and $60 \mathrm{~s}$ at $72{ }^{\circ} \mathrm{C}$ followed by one cycle of $60 \mathrm{~s}$ at $95^{\circ} \mathrm{C}, 30 \mathrm{~s}$ at $55^{\circ} \mathrm{C}$, and $30 \mathrm{~s}$ at $95^{\circ} \mathrm{C}$. The specificity of the amplification reaction for each primer pair was determined by the melting curve. Transcript levels within samples were normalized to the eukaryotic translation initiation factor 3 subunit $\mathrm{H}$. $\log _{2}{ }^{\text {(Fold Change) }}$ was calculated using $-\Delta \Delta \mathrm{Ct}=-\left[\left(\mathrm{Ct}_{\mathrm{GOI}}-\mathrm{Ct}_{\text {nom }}\right)_{\mathrm{Mu}^{-} \text {Legacy }}-\left(\mathrm{Ct}_{\mathrm{GOI}}-\mathrm{Ct}_{\text {nom }}\right)_{\text {Legacy }}\right]$ for each transgenic Mu-Legacy versus a non-transgenic 'Legacy' sample $(n=3)$ [42].

\subsection{Gene Network Construction}

Annotated transcripts were imported to Cytoscape 3.5.0 under BiNGO's default parameters with the selected ontology file 'GOSlim_Plants' and selected organism A. thaliana $[43,44]$.

\section{Conclusions}

The DE VcCORs identified in the comparisons of transcriptomes of eight tissues revealed the specificity of the VcCORs expression in different tissues and different chilling stages. VcDDF1 was not cold inducible; however, overexpression of the $V c D D F 1$ increased freezing tolerance through its impact on the other DE VcCORs. The results of this study will facilitate future studies on improving blueberry cold hardiness through manipulating VcCORs.

Supplementary Materials: Supplementary materials can be found at http:/ /www.mdpi.com/1422-0067/19/6/ $1553 /$ s1.

Author Contributions: G.S. conceived the study; G.S. and A.W. conducted the experiments; G.S. analyzed the data; and G.S. and A.W. wrote the manuscript. All authors read and approved the manuscript.

Acknowledgments: The authors would thank Jeff Landgraf and Kevin Carr at the Michigan State University Research Technology Support Facility for RNA sequencing. This research is partially supported by AgBioResearch Project GREEEN of Michigan State University (Available online: http:/ /agbioresearch.msu.edu/project_greeen).

Conflicts of Interest: The authors declare no conflict of interest.

\section{References}

1. Pearce, R.S. Plant freezing and damage. Ann. Bot. 2001, 87, 417-424. [CrossRef]

2. Li, C.Y.; Puhakainen, T.; Welling, A.; Vihera-Aarnio, A.; Ernstsen, A.; Junttila, O.; Heino, P.; Pavla, E.T. Cold acclimation in silver birch (Betula pendula). Development of freezing tolerance in different tissues and climatic ecotypes. Physiol. Plant. 2002, 116, 478-488. [CrossRef]

3. Strimbeck, G.R.; Schaberg, P.G.; Fossdal, C.G.; Schroder, W.P.; Kjellsen, T.D. Extreme low temperature tolerance in woody plants. Front. Plant Sci. 2015, 6, 884. [CrossRef] [PubMed]

4. Larcher, W. Physiological Plant Ecology: Ecophysiology and Stress Physiology of Functional Groups, 4th ed.; Springer: Berlin, Germany; New York, NY, USA, 2003; p. xx. 513p.

5. Kreyling, J.; Schmid, S.; Aas, G. Cold tolerance of tree species is related to the climate of their native ranges. J. Biogeogr. 2015, 42, 156-166. [CrossRef]

6. Chuine, I.C.; Bonhomme, M.; Legave, J.-M.; De Cortázar-atauri, I.; Charrier, G.; Lacointe, A.; Améglio, T. Can phenological models predict tree phenology accurately in the future? The unrevealed hurdle of endodormancy break. Glob. Chang. Biol. 2016, 22, 3444-3460. [CrossRef] [PubMed] 
7. Root, T.L.; Price, J.T.; Hall, K.R.; Schneider, S.H.; Rosenzweig, C.; Pounds, J.A. Fingerprints of global warming on wild animals and plants. Nature 2003, 421, 57-60. [CrossRef] [PubMed]

8. Parmesan, C.; Yohe, G. A globally coherent fingerprint of climate change impacts across natural systems. Nature 2003, 421, 37-42. [CrossRef] [PubMed]

9. Atkinson, C.J.; Brennan, R.M.; Jones, H.G. Declining chilling and its impact on temperate perennial crops. Environ. Exp. Bot. 2013, 91, 48-62. [CrossRef]

10. Luedeling, E.; Girvetz, E.H.; Semenov, M.A.; Brown, P.H. Climate change affects winter chill for temperate fruit and nut trees. PLoS ONE 2011, 6, e20155. [CrossRef] [PubMed]

11. Melke, A. The Physiology of Chilling Temperature Requirements for Dormancy Release and Bud-break in Temperate Fruit Trees Grown at Mild Winter Tropical Climate. J. Plant Stud. 2015, 4, 110-156. [CrossRef]

12. Park, S.; Lee, C.M.; Doherty, C.J.; Gilmour, S.J.; Kim, Y.; Thomashow, M.F. Regulation of the Arabidopsis CBF regulon by a complex low-temperature regulatory network. Plant J. 2015, 82, 193-207. [CrossRef] [PubMed]

13. Shi, Y.; Huang, J.; Sun, T.; Wang, X.; Zhu, C.; Ai, Y.; Gu, H. The precise regulation of different COR genes by individual CBF transcription factors in Arabidopsis thaliana. J. Integr. Plant. Biol. 2017, 59, 118-133. [CrossRef] [PubMed]

14. Berdeja, M.; Nicolas, P.; Kappel, C.; Dai, Z.W.; Hilbert, G.; Peccoux, A.; Lafontaine, M.; Ollat, N.; Gomes, E.; Delrot, S. Water limitation and rootstock genotype interact to alter grape berry metabolism through transcriptome reprogramming. Hortic. Res. 2015, 2, 15012. [CrossRef] [PubMed]

15. Thomashow, M.F.; Gilmour, S.J.; Stockinger, E.J.; Jaglo-Ottosen, K.R.; Zarka, D.G. Role of the Arabidopsis CBF transcriptional activators in cold acclimation. Physiol. Plant. 2001, 112, 171-175. [CrossRef]

16. Miller, A.K.; Galiba, G.; Dubcovsky, J. A cluster of 11 CBF transcription factors is located at the frost tolerance locus Fr-A $\left({ }^{\mathrm{m}}\right) 2$ in Triticum monococcum. Mol. Genet. Genom. 2006, 275, 193-203. [CrossRef] [PubMed]

17. Mizoi, J.; Shinozaki, K.; Yamaguchi-Shinozaki, K. AP2/ERF family transcription factors in plant abiotic stress responses. Biochim. Biophys. Acta 2012, 1819, 86-96. [CrossRef] [PubMed]

18. Carvallo, M.A.; Pino, M.T.; Jeknic, Z.; Zou, C.; Doherty, C.J.; Shiu, S.H.; Chen, T.H.H.; Thomashow, M.F. A comparison of the low temperature transcriptomes and CBF regulons of three plant species that differ in freezing tolerance: Solanum commersonii, Solanum tuberosum, and Arabidopsis thaliana. J. Exp. Bot. 2011, 62, 3807-3819. [CrossRef] [PubMed]

19. Liu, Q.; Kasuga, M.; Sakuma, Y.; Abe, H.; Miura, S.; Yamaguchi-Shinozaki, K.; Shinozaki, K. Two transcription factors, DREB1 and DREB2, with an EREBP/AP2 DNA binding domain separate two cellular signal transduction pathways in drought- and low-temperature-responsive gene expression, respectively, in Arabidopsis. Plant Cell 1998, 10, 1391-1406. [CrossRef] [PubMed]

20. Gilmour, S.J.; Zarka, D.G.; Stockinger, E.J.; Salazar, M.P.; Houghton, J.M.; Thomashow, M.F. Low temperature regulation of the Arabidopsis CBF family of AP2 transcriptional activators as an early step in cold-induced COR gene expression. Plant J. 1998, 16, 433-442. [CrossRef] [PubMed]

21. Stockinger, E.J.; Gilmour, S.J.; Thomashow, M.F. Arabidopsis thaliana CBF1 encodes an AP2 domaincontaining transcriptional activator that binds to the C-repeat/DRE, a cis-acting DNA regulatory element that stimulates transcription in response to low temperature and water deficit. Proc. Natl. Acad. Sci. USA 1997, 94, 1035-1040. [CrossRef] [PubMed]

22. Jaglo-Ottosen, K.R.; Gilmour, S.J.; Zarka, D.G.; Schabenberger, O.; Thomashow, M.F. Arabidopsis CBF1 overexpression induces COR genes and enhances freezing tolerance. Science 1998, 280, 104-106. [CrossRef] [PubMed]

23. El Kayal, W.; Navarro, M.; Marque, G.; Keller, G.; Marque, C.; Teulieres, C. Expression profile of CBF-like transcriptional factor genes from Eucalyptus in response to cold. J. Exp. Bot. 2006, 57, 2455-2469. [CrossRef] [PubMed]

24. Navarro, M.; Ayax, C.; Martinez, Y.; Laur, J.; El Kayal, W.; Marque, C.; Teulieres, C. Two EguCBF1 genes overexpressed in Eucalyptus display a different impact on stress tolerance and plant development. Plant Biotechnol. J. 2011, 9, 50-63. [CrossRef] [PubMed]

25. Wisniewski, M.; Norelli, J.; Artlip, T. Overexpression of a peach CBF gene in apple: A model for understanding the integration of growth, dormancy, and cold hardiness in woody plants. Front. Plant Sci. 2015, 6, 85. [CrossRef] [PubMed] 
26. Tillett, R.L.; Wheatley, M.D.; Tattersall, E.A.; Schlauch, K.A.; Cramer, G.R.; Cushman, J.C. The Vitis vinifera C-repeat binding protein $4(\mathrm{VvCBF} 4)$ transcriptional factor enhances freezing tolerance in wine grape. Plant Biotechnol. J. 2012, 10, 105-124. [CrossRef] [PubMed]

27. Oakenfull, R.J.; Baxter, R.; Knight, M.R. A C-repeat binding factor transcriptional activator (CBF/DREB1) from European bilberry (Vaccinium myrtillus) induces freezing tolerance when expressed in Arabidopsis thaliana. PLoS ONE 2013, 8, e54119. [CrossRef] [PubMed]

28. Jin, W.M.; Dong, J.; Hu, Y.L.; Lin, Z.P.; Xu, X.F.; Han, Z.H. Improved Cold-resistant Performance in Transgenic Grape (Vitis vinifera L.) Overexpressing Cold-inducible Transcription Factors AtDREB1b. Hortscience 2009, 44, 35-39.

29. Owens, C.L.; Thomashow, M.F.; Hancock, J.F.; Iezzoni, A.F. CBF1 orthologs in sour cherry and strawberry and the heterologous expression of CBF1 in strawberry. J. Am. Soc. Hortic. Sci. 2002, 127, 489-494.

30. USDA-NASS. Noncitrus Fruits and Nuts-2016 Summary. June 2017. Available online: http:/ / usda.mannlib. cornell.edu/usda/current/NoncFruiNu/NoncFruiNu-06-27-2017.pdf (accessed on 7 March 2018).

31. Longstroth, M.; Hanson, E. The Michigan Blueberry Industry. Michigan State University Extension. 2012, p. 5. Available online: http://msue.anr.msu.edu/uploads/files/The_Michigan_Blueberry_Industry_2012_ MSUE_online.pdf (accessed on 7 March 2018).

32. Rowland, L.J.; Ogden, E.L.; Ehlenfeldt, M.K.; Arora, R. Cold Tolerance of Blueberry Genotypes Throughout the Dormant Period from Acclimation to Deacclimation. Hortscience 2008, 43, 1970-1974.

33. Walworth, A.E.; Rowland, L.J.; Polashock, J.J.; Hancock, J.F.; Song, G.Q. Overexpression of a blueberryderived $\mathrm{CBF}$ gene enhances cold tolerance in a southern highbush blueberry cultivar. Mol. Breed. 2012, 30, 1313-1323. [CrossRef]

34. Song, G.Q.; Gao, X. Transcriptomic changes reveal gene networks responding to the overexpression of a blueberry DWARF AND DELAYED FLOWERING 1 gene in transgenic blueberry plants. BMC Plant Biol. 2017, 17, 106. [CrossRef] [PubMed]

35. Rowland, L.J.; Alkharouf, N.; Darwish, O.; Ogden, E.L.; Polashock, J.J.; Bassil, N.V.; Main, D. Generation and analysis of blueberry transcriptome sequences from leaves, developing fruit, and flower buds from cold acclimation through deacclimation. BMC Plant Biol. 2012, 12, 46. [CrossRef] [PubMed]

36. Fowler, S.; Thomashow, M.F. Arabidopsis transcriptome profiling indicates that multiple regulatory pathways are activated during cold acclimation in addition to the CBF cold response pathway. Plant Cell 2002, 14, 1675-1690. [CrossRef] [PubMed]

37. Qin, F.; Shinozaki, K.; Yamaguchi-Shinozaki, K. Achievements and challenges in understanding plant abiotic stress responses and tolerance. Plant Cell Physiol. 2011, 52, 1569-1582. [CrossRef] [PubMed]

38. Thomashow, M.F. Molecular basis of plant cold acclimation: insights gained from studying the CBF cold response pathway. Plant Physiol. 2010, 154, 571-577. [CrossRef] [PubMed]

39. Polashock, J.J.; Arora, R.; Peng, Y.; Naik, D.; Rowland, L.J. Functional Identification of a C-repeat Binding Factor Transcriptional Activator from Blueberry Associated with Cold Acclimation and Freezing Tolerance. J. Am. Soc. Hortic. Sci. 2010, 135, 40-48.

40. Haas, B.J.; Papanicolaou, A.; Yassour, M.; Grabherr, M.; Blood, P.D.; Bowden, J.; Couger, M.B.; Eccles, D.; Li, B.; Lieber, M.; et al. De novo transcript sequence reconstruction from RNA-seq using the Trinity platform for reference generation and analysis. Nat. Protoc. 2013, 8, 1494-1512. [CrossRef] [PubMed]

41. Walworth, A.E.; Chai, B.; Song, G.Q. Transcript Profile of Flowering Regulatory Genes in VcFTOverexpressing Blueberry Plants. PLoS ONE 2016, 11, e0156993. [CrossRef] [PubMed]

42. Livak, K.J.; Schmittgen, T.D. Analysis of relative gene expression data using real-time quantitative PCR and the 2(-Delta Delta C(T)) Method. Methods 2001, 25, 402-408. [CrossRef] [PubMed]

43. Shannon, P.; Markiel, A.; Ozier, O.; Baliga, N.S.; Wang, J.T.; Ramage, D.; Amin, N.; Schwikowski, B.; Ideker, T. Cytoscape: A software environment for integrated models of biomolecular interaction networks. Genome Res. 2003, 13, 2498-2504. [CrossRef] [PubMed]

44. Maere, S.; Heymans, K.; Kuiper, M. BiNGO: A Cytoscape plugin to assess overrepresentation of gene ontology categories in biological networks. Bioinformatics 2005, 21, 3448-3449. [CrossRef] [PubMed]

(C) 2018 by the authors. Licensee MDPI, Basel, Switzerland. This article is an open access article distributed under the terms and conditions of the Creative Commons Attribution (CC BY) license (http:/ / creativecommons.org/licenses/by/4.0/). 